University of Wollongong

Research Online

Faculty of Engineering and Information

Faculty of Engineering and Information

Sciences - Papers: Part A

Sciences

$1-1-2012$

Dynamic characteristics of a hybrid microgrid with inverter and noninverter interfaced renewable energy sources: A case study

\author{
A V. Jayawardena \\ University of Wollongong, avj998@uowmail.edu.au \\ L G. Meegahapola \\ University of Wollongong, lasantha.meegahapola@rmit.edu.au \\ S Perera \\ University of Wollongong, sarath@uow.edu.au \\ D A. Robinson \\ University of Wollongong, duane@uow.edu.au
}

Follow this and additional works at: https://ro.uow.edu.au/eispapers

Part of the Engineering Commons, and the Science and Technology Studies Commons

Research Online is the open access institutional repository for the University of Wollongong. For further information contact the UOW Library: research-pubs@uow.edu.au 


\title{
Dynamic characteristics of a hybrid microgrid with inverter and non- inverter interfaced renewable energy sources: A case study
}

\begin{abstract}
Microgrids are becoming important constituents of electric power distribution networks. Microgrids are typically comprised of both inverter interfaced (e.g. double-fed induction generator (DFIG), solarphotovoltaic (PV) system) and non-inverter interfaced (e.g. synchronous generator) renewable energy generators (REGs), hence their dynamic characteristics are significantly different from the conventional grids comprised of centralised synchronous generators. Different inherent characteristics of REGs, power dispatch levels, relative REG capacities, and external grid characteristics are some of the important features of significant interest in relation to microgrid dynamic behaviour. For this study a microgrid model was developed in DIgSILENT Power Factory based on the IEEE-13 bus system and comparative analysis has been carried out between inverter and non-inverter based REGs. The study has shown that variations in active power dispatch levels and generator relative sizing significantly influence dynamic characteristics of the microgrid hence adequate measures must be taken when designing protection schemes for microgrids. In addition, dynamic reactive power compensation and emulated frequency response schemes must be implemented in microgrids to preserve voltage and frequency stability when operating in islanded mode.
\end{abstract}

\section{Keywords}

non, inverter, microgrid, hybrid, study, case, sources, characteristics, energy, dynamic, renewable, interfaced

\section{Disciplines}

Engineering | Science and Technology Studies

\section{Publication Details}

A. V. Jayawardena, L. G. Meegahapola, S. Perera \& D. A. Robinson, "Dynamic characteristics of a hybrid microgrid with inverter and non- inverter interfaced renewable energy sources: A case study," in IEEE International Conference on Power System Technology (POWERCON), 2012, pp. 1-6. 


\title{
Dynamic Characteristics of a Hybrid Microgrid with Inverter and Non- Inverter Interfaced Renewable Energy Sources: A Case Study
}

\author{
A.V. Jayawardena, Student Member, IEEE, L.G. Meegahapola, Member IEEE, S. Perera, Member IEEE, \\ D.A. Robinson
}

\begin{abstract}
Microgrids are becoming important constituents of electric power distribution networks. Microgrids are typically comprised of both inverter interfaced (e.g. double-fed induction generator (DFIG), solar-photovoltaic (PV) system) and noninverter interfaced (e.g. synchronous generator) renewable energy generators (REGs), hence their dynamic characteristics are significantly different from the conventional grids comprised of centralised synchronous generators. Different inherent characteristics of REGs, power dispatch levels, relative REG capacities, and external grid characteristics are some of the important features of significant interest in relation to microgrid dynamic behaviour.

For this study a microgrid model was developed in DIgSILENT Power Factory based on the IEEE-13 bus system and comparative analysis has been carried out between inverter and non-inverter based REGs. The study has shown that variations in active power dispatch levels and generator relative sizing significantly influence dynamic characteristics of the microgrid hence adequate measures must be taken when designing protection schemes for microgrids. In addition, dynamic reactive power compensation and emulated frequency response schemes must be implemented in microgrids to preserve voltage and frequency stability when operating in islanded mode.
\end{abstract}

Index Terms-Double-fed induction generator (DFIG), dynamic behaviour, frequency stability, mini-hydro power plant, microgrid, rate of change of frequency (ROCOF), solarphotovoltaic (PV).

\section{INTRODUCTION}

$\mathrm{I}_{\mathrm{N}}^{\mathrm{N}}$ NTEGRATION of renewable energy generators (REGs) into electrical power distribution networks has gathered momentum in the recent years due to policy directives on reduction in greenhouse gas (GHG) emission from electrical power generation. At the same time, it is also seen that penetration of REGs in some cases has mitigated the need for expansion of traditional power network, increased reliability, and improved energy efficiency through localised generation and demand side management $[1,2]$.

A.V. Jayawardena, is a $\mathrm{PhD}$ candidate at the School of Electrical, Computer and Telecommunications Engineering at the University of Wollongong, NSW, 2522, Australia (e-mail: avj998@uowmail.edu.au).

L.G. Meegahapola, is a Lecturer with the Endeavour Energy Power Quality \& Reliability Centre at the University of Wollongong, NSW, 2522, Australia. (e-mail lasantha@uow.edu.au).

S. Perera is the Director of the Endeavour Energy Power Quality \& Reliability Centre and an Associate Professor at the University of Wollongong, NSW, 2522, Australia (e-mail: sarath@uow.edu.au).

D.A. Robinson is a Senior Lecturer with the Sustainable Buildings Research Centre at the University of Wollongong, NSW, 2522, Australia (email: duane@uow.edu.au).
REG technologies typically include wind turbines, microturbines and other cogeneration plants, photovoltaic (PV) systems, fuel cells and small scale hydro generators. These technologies can be combined with associated load within the power network to form a microgrid [3, 4]. Batteries, super capacitors and fly wheels are also often present in microgrids as energy storage devices [5]. Environmental and economic advantages, emphasis on demand side integration, and improvement of power quality and reliability have reinforced the development of the microgrid concept as a sustainable energy supply strategy for distribution networks.

From the perspective of the main grid, a microgrid can be seen as a single controllable entity somewhat similar to a large conventional generation unit. Microgrids can also have the capability to operate in islanded mode during planned and unplanned switching events of the upstream network [6, 7]. With the expanding number and size of microgrids, associated technical challenges such as (a) Power quality and reliability issues, (b) Protection coordination, and (c) Dynamic stability issues will no doubt increase [1]. Out of these, dynamic stability issues that arise due to systems with simultaneously present non-inverter interfaced REGs and inverter interfaced REGs (e.g. conventional generator and PV system) have received very little attention.

A range of aspects such as different inherent characteristics of REG, different power dispatch levels, generator capacities, and external grid characteristics will play prominent roles in successful operation of microgrids in the future. This paper presents a case study carried out focusing on those aspects. The importance of understanding the dynamic behaviour of microgrids is highlighted through a comparative analysis undertaken on a hybrid microgrid containing solar-PV system, double-fed induction generator (DFIG), and synchronous generator such as mini-hydro power plant (MHPP) developed in DIgSILENT Power Factory. The structure of the paper is as follows; Section II presents a critical review on dynamic studies conducted on microgrids. Section III describes the microgrid model and simulation models of the REGs used in the study. Section IV and V present a comparative analysis between inverter and non-inverter based REGs. Finally conclusions of the study are presented in Section VI.

\section{DYNAMIC BEHAVIOUR OF MICROGRIDS - A REVIEW}

Comprehensive transient and small-signal stability assessment is considered as a significant technical challenge associated with future microgrids. This section presents a critical review of literature related to dynamics of microgrids. 
Dynamic behaviour of a microgrid due to unplanned islanding mainly depends on the following few factors; pre planned operating conditions, type and location of the fault, islanding detection time, types of REG within the microgrid and post fault switching actions of the system. It is important to have fast and accurate islanding detection methods in microgrids in order to maintain stability. System studies in [8] based on one synchronous generator (SG) and an inverter interfaced distributed generator carried out during and subsequent to islanding of a microgrid illustrate the importance of having properly controlled inverter interfaced REG. Such control can minimise the adverse impacts due to planned and un-planned islanding of a microgrid. Through various simulation scenarios, it has been identified that without fast control actions of inverter interfaced REGs, network disturbances can result in frequency and power oscillations in the microgrid.

Investigations have been carried out in [9] on power management strategies (PMS) for an islanded microgrid based on reactive power control and active power control methods. Three reactive power control strategies have been proposed based on; (1) voltage droop characteristics (2) voltage regulation, and (3) load reactive power compensation. A real power control strategy has been developed based on droop characteristics and a complimentary frequency restoration method. A microgrid with two inverter interfaced REGs and a single synchronous generator in a $13.8 \mathrm{kV}$ distribution network has been developed to investigate small-signal dynamics of a linearised microgrid model. Eigenvalue analysis has been carried out on two scenarios based on PMSs. It has been identified that the stability margin increases when real power is mainly supplied by inverter interfaced REGs. However, analysis of system oscillatory modes has revealed that mechanical oscillatory modes of the conventional generator have a strong effect on dynamic behaviour of the microgrid. Further, these oscillatory modes do not depend on the PMS implemented in the microgrid. It is suggested that load shedding schemes should be incorporated in islanded mode when the generation cannot fulfil the load demand. According to the study, voltage regulation or reactive power compensation is more suitable as the reactive power management strategy for REGs located close to each other.

Small signal stability studies have been carried out using time domain simulations in [10] on an islanded microgrid comprising wind turbine generators, a PV system, a diesel generator, fuel cells, a battery storage system and a flywheel system. Simplified transfer functions have been used to represent the REGs while power losses and controllers have been ignored in the studies.

A systematic approach for small signal modelling of inverter based autonomous microgrid is presented in [11]. According to the study, grid connected microgrid dynamics have been determined mainly by the utility grid due to the relatively insignificant capacity of the REG. However, in islanded mode, local REG mainly determine the dynamic behaviour of the microgrid. During sudden load transients, REG nearest to the load changes respond quickly depending on the effective impedance seen from the load point. Due to the significant resistance present in the distribution network, considerable reactive power exchange between the inverters for an active power variation has been observed. This has been compensated to some extent by increasing the droop in the voltage controllers.

A strategy to reduce oscillations during synchronisation is presented in [12] with investigations on interactions between non-inverter interfaced (based on diesel generators) and inverter interfaced REGs in an islanded microgrid. According to their results, frequency and active power oscillations are less for the inverter interfaced REGs compared to non-inverter interfaced REGs. Voltage angle based droop control strategy was proposed for inverter interfaced REGs to reduce the frequency oscillations in the microgrid.

A new control strategy applicable to a DFIG which can provide voltage and frequency regulation capabilities is presented in [13]. Dynamic performance of a microgrid during islanded and grid connected modes have been improved by using DFIGs with such capabilities. Dynamic studies have been carried out using a DFIG and an SG while operating them at constant power factor mode (closer to unity). The study suggests that post transient power and frequency oscillations in a microgrid could be damped by implementing a primary frequency control strategy in the DFIG.

Stability investigation of an islanded microgrid based on a diesel generator and inverter interfaced REGs, and their control interactions were analysed in [14]. In the study, inverter interfaced REGs have been represented as constant DC voltage sources interfaced via three-phase inverters. An eigenvalue analysis and time domain simulations were undertaken on the islanded microgrid model. According to the study, power-frequency droop of the inverter interfaced REGs does not have a significant impact on the system stability compared to the diesel generators.

Based on critical review of the relevant literature considered in this section, some important aspects in dynamic stability studies which require special attention have been identified. In many occasions, a generalised model of inverter interfaced REGs have been used in dynamic stability studies $[8-9,11-12,14]$ or focused only on a single type of inverter interfaced REG [13]. However, due to unique dynamic characteristics of REGs it is important to represent REGs using a detailed model in dynamic simulations. With the increasing penetration of different generation technologies in networks as stated in Section I, it is important to consider different combinations of REGs in dynamic studies. Controllers have been ignored in [10] while the importance of implementing proper control strategies in microgrids is highlighted in [14]. Much interest has been given to islanded microgrids. However, it is also important to investigate microgrid dynamic behaviour in grid connected mode with various REG and to analyse the effects of external grid on microgrid stability. Further, microgrids with mini-hydro generators based on SGs have received less attention in dynamic stability studies. The following sections will present case studies focusing on some of these aspects covering (a) different inherent characteristics of REGs, (b) power dispatch levels, (c) relative REG capacities, and (d) external grid characteristics on microgrid voltage and frequency behaviour. 


\section{MICROGRID TEST MODEL AND RENEWABLE GENERATOR MODELS}

Simulations were carried out using a microgrid model developed in the DIgSILENT Power Factory. The REGs were modelled using the DIgSILENT simulation language (DSL). This section presents modelling descriptions of the microgrid and renewable energy generators used in the study.

\section{A. Microgrid model}

The IEEE-13 bus model was used to analyse the dynamic behaviour of a microgrid with inverter and non-inverter based renewable energy generators. Fig. 1 illustrates the single line diagram of a $4.16 \mathrm{kV}$ IEEE-13 bus model designed in DIgSILENT Power Factory for this dynamic study.

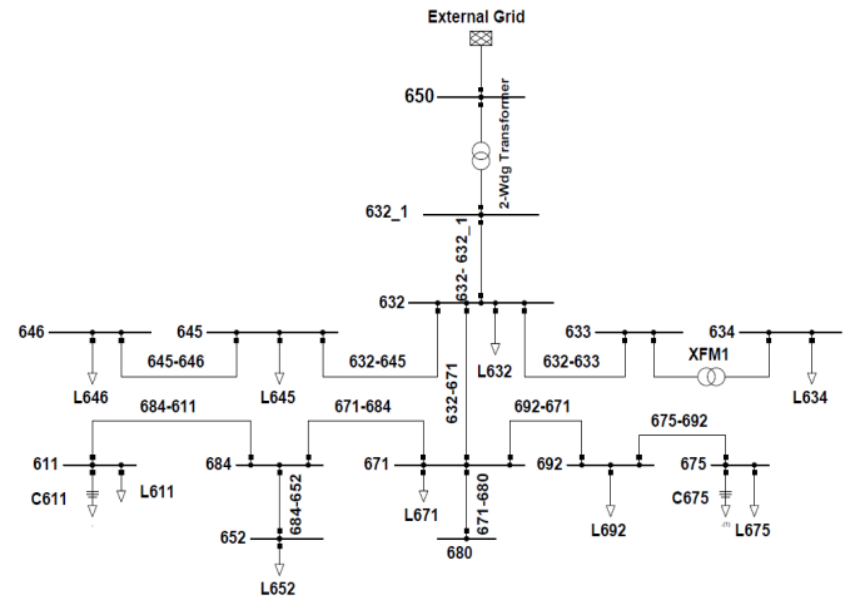

Fig. 1. Modified IEEE-13 bus system microgrid model.

Necessary modifications were made in the IEEE-13 node test feeder [15] to obtain a balanced microgrid. The total active and reactive power demand of the microgrid are 3.8 MW and 2.4 MVAr respectively. Two switched shunt capacitor banks were installed at buses 611 and 675 to provide the reactive power support to the microgrid. The microgrid voltage was maintained between $0.95-1.05 \mathrm{pu}$, and it was connected to the external grid through a $115 / 4.16 \mathrm{kV}$, 10 MVA transformer. Three types of REGs namely; Minihydro power plant (MHPP), DFIG and PV system are considered in the study.

\section{B. Mini-hydro power plant}

The plant model of the synchronous generator represents a MHPP. The hydro turbine governor model in [16] and IEEE type AC1A excitation system in [17] have been used to implement the MHPP model.

\section{DFIG model}

Fig. 2 illustrates the DFIG simulation model developed in DIgSILENT Power Factory [18]. The DFIG was modelled as a three-mass model (i.e. turbine, drive train and generator inertia) and operates at unity power factor mode. Fig. 2 illustrates the functional block diagram of the simulation model developed in DIgSILENT power factory.

The active and reactive power was controlled by both PQ and fast current controller of the DFIG model. The current controller is consisted of a damping controller hence it can quickly dampen the power oscillations at the PCC. The crowbar protection was employed to protect the rotor-side converter from large rotor current transients during faults.

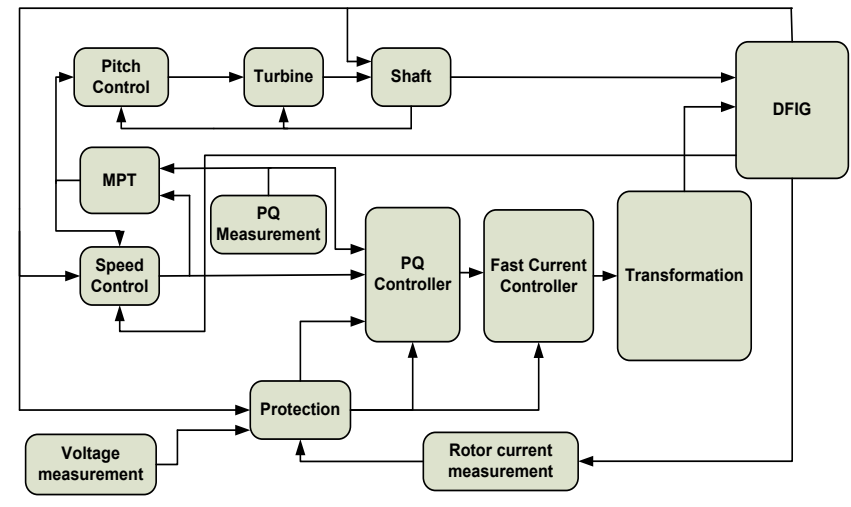

Fig. 2. DFIG simulation model.

\section{Solar-PV model}

Fig. 3 illustrates the solar-PV model developed in DIgSILENT Power Factory. The solar-PV system operates at power factor mode while the irradiance level and temperature were assumed to be constant during dynamic studies.

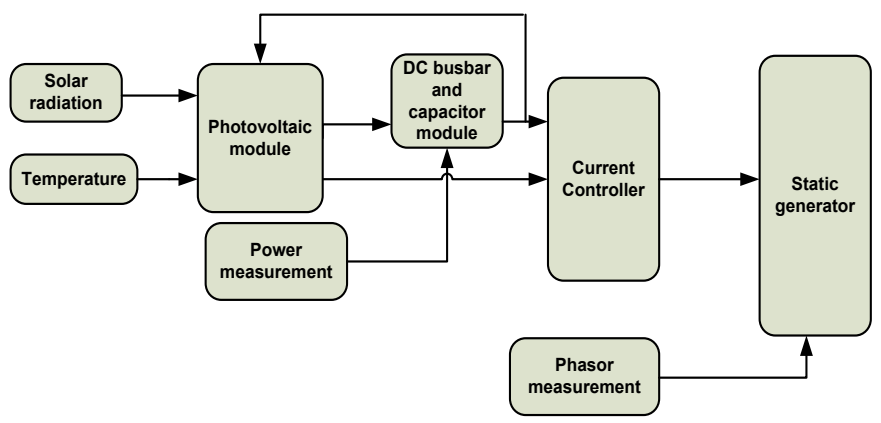

Fig. 3. Solar-PV simulation model.

\section{MICROGRID DYNAMICS DURING UNPLANNED ISLANDING}

Simulation scenarios have been formulated to investigate the dynamics associated with unplanned islanding of the microgrid. During the grid connected mode microgrid generates $4 \mathrm{MW}$ of active power whiles the external grid supplies 1.38 MVAr reactive power support to the microgrid. The following scenarios have been analysed in the study; effect of SG inertia, REG machine MVA rating, REG active power dispatch level, and different types of REG combinations.

\section{A. Different machine ratings}

Different active power combinations between inverter (e.g. DFIG and PV) and non-inverter based (MHPP) REGs were analysed while installing generators with different MVA ratings. Therefore, generators are operated at their rated active power output to cater active power demand of the microgrid. Synchronous generator inertia constant $(H)$ was altered according to the machine capacity in order to maintain stored energy constant. The following two scenarios were analysed;

- Scenario 1: In this scenario, a MHPP (SG) and a DFIG were connected to buses 646 and 680 respectively to supply the active power demand of the microgrid.

- Scenario 2: DFIG was replaced with a PV system having same power rating. 
Fig. 4 illustrate the frequency response of the microgrid when external grid was disconnected at $t=5 \mathrm{~s}$.

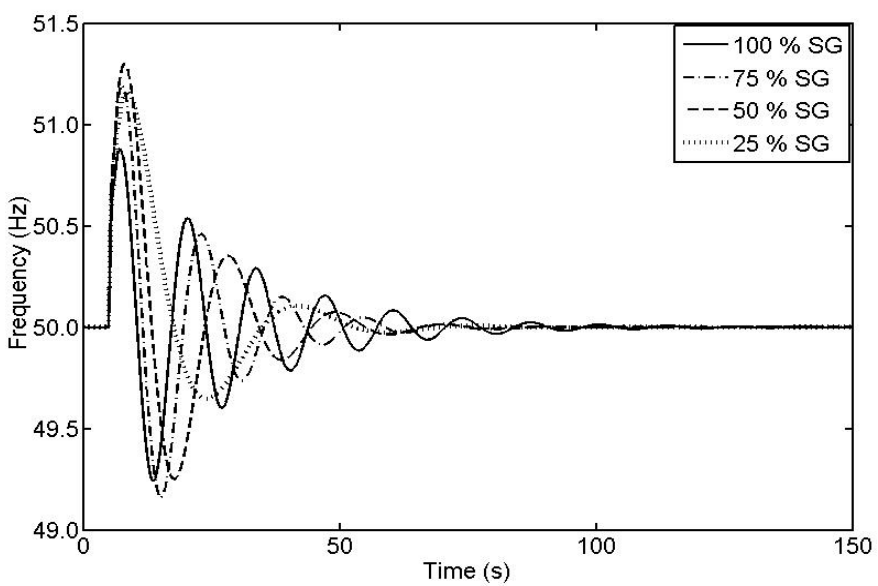

(a)

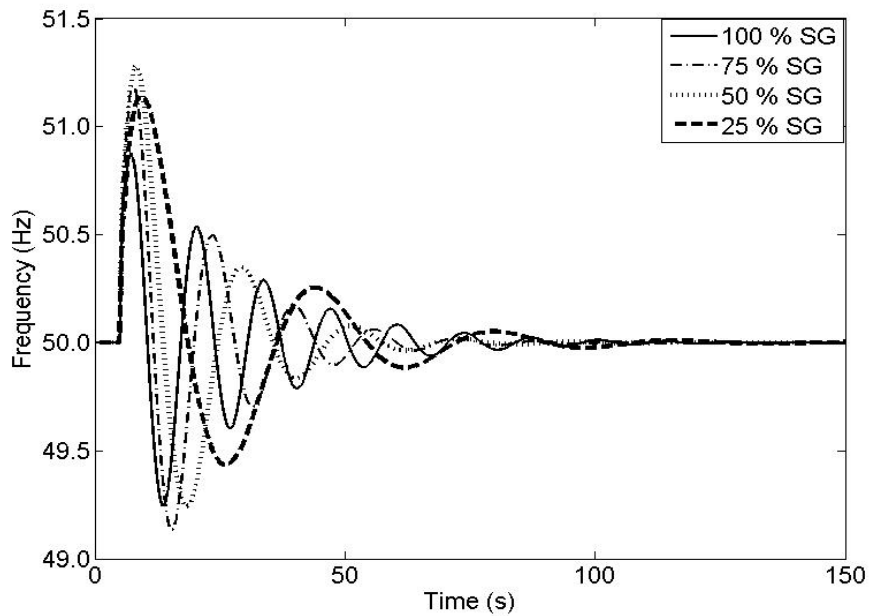

(b)

Fig. 4. Microgrid frequency variations for different machine ratings during unplanned islanding: (a) DFIG and MHPP; (b) PV and MHPP (different $H$ for $\mathrm{SG})$.

Both Figs. 4(a) and 4(b) exhibit similar responses to unplanned islanding of the microgrid, independent of whether it contains a DFIG or a PV system of the same capacity. Further, they also illustrate the significant difference in the oscillatory behaviour exhibited by inverter based REGs (e.g. $25 \% \mathrm{SG}$ ) in comparison to that of non-inverter based REGs (100\% SG). Penetration of non-inverter based REGs has a significant effect on improving the damping of power frequency oscillations due to artificial damping provided by the fast current controllers of both DFIG and solar-PV model (refer to Fig. 2 and Fig. 3). Table I summarises the maximum rate of change of frequency (ROCOF) of the microgrid for both scenarios.

TABLE I

Maximum ROCOF of the microgrid with DFIG and SG

\begin{tabular}{c||c||c}
\hline \multicolumn{1}{c||}{ Installed capacity } & \multicolumn{2}{c}{ Maximum ROCOF $(\mathrm{Hz} / \mathrm{s})$} \\
\hline & DFIG and SG & PV and SG \\
\hline $25 \% \mathrm{SG}$ & 0.2577 & 0.2525 \\
\hline $50 \% \mathrm{SG}$ & 0.1743 & 0.1542 \\
\hline $75 \% \mathrm{SG}$ & 0.0990 & 0.0737 \\
\hline $100 \% \mathrm{SG}$ & 0.0289 & 0.0281 \\
\hline
\end{tabular}

Following the disturbance caused by unplanned islanding, the converter of the DFIG quickly controls the power output to pre-fault value since it decouples the inertial response of the turbines from the system. Due to lack of inertial response from DFIG and solar-PV, inertial response is provided only by the SG in the microgrid. Hence, effective angular acceleration of the SG would increase, resulting in an increase in maximum ROCOF. This can be clearly observed from Table I where the maximum ROCOF occurs with $25 \%$ of SG in the microgrid. Therefore, when designing protection schemes for a microgrid consisted of both inverter and non-inverter based generation technologies the proportion of each type of must be explicitly considered in the design process. Table II presents the minimum voltage at the grid connection point as a percentage of steady-state voltage during unplanned islanding of the microgrid.

TABLE II

Minimum voltage magnitude as a percentage of steady-state voltage with DFIG and SG during unplanned islanding

\begin{tabular}{c||c}
\hline Installed capacity & Minimum voltage / Steady state voltage (\%) \\
\hline $25 \% \mathrm{SG}$ & 91.1 \\
\hline $50 \% \mathrm{SG}$ & 92.9 \\
\hline $75 \% \mathrm{SG}$ & 93.0 \\
\hline $100 \% \mathrm{SG}$ & 93.4 \\
\hline
\end{tabular}

It can be observed that with the increased penetration of $\mathrm{SG}$, voltage dip reduces due to the reactive power support provided by the SGs. However, the voltage dip resulting from unplanned islanding still remains within the safe operating region of the ITI (CBEMA) curve [19], hence the impact on electrical appliances in the microgrid is minimal.

\section{B. Different dispatch levels}

In this scenario, 5 MVA MHPP (SG) and 4.5 MVA DFIG have been connected to bus 646 and bus 680 respectively. Different to previous scenarios, only active power dispatch levels of SG and DFIG were changed while maintaining machine capacity constant. Fig. 5 illustrates the frequency behaviour of the microgrid when the external grid was disconnected at $t=5 \mathrm{~s}$.

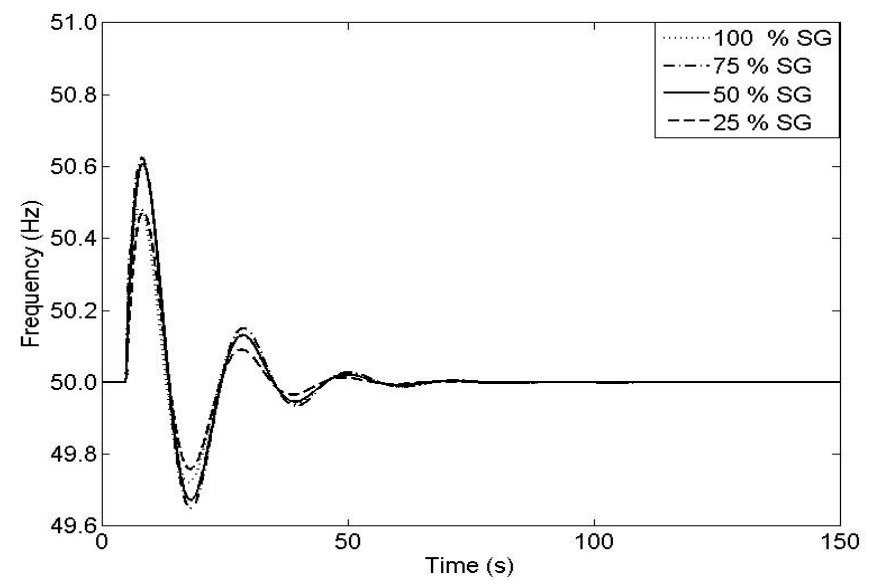

Fig. 5. Microgrid frequency variations for different active power dispatch levels of SG and DFIG during unplanned islanding.

As illustrated in Fig. 5, with the reduction of active power dispatch from the SG, frequency excursion and maximum ROCOF increases as seen in the previous section due to the increased non-inertial (i.e. DFIG) power generation in the 
microgrid. However, frequency excursion and ROCOF has significantly reduced in comparison to the previous scenario (Section IV-A) due to increased MVA capacity of the generators (effective stored energy has increased).

TABLE III

Minimum voltage magnitude as a percentage of steady-state voltage with DFIG and SG during unplanned islanding

\begin{tabular}{c||c}
\hline \multicolumn{1}{c||}{ Installed capacity of SG } & $\begin{array}{c}\text { Minimum voltage / Steady state voltage } \\
(\%)\end{array}$ \\
\hline $25 \%$ & 92.8 \\
\hline $50 \%$ & 94.7 \\
\hline $75 \%$ & 96.5 \\
\hline $100 \%$ & 98.2 \\
\hline
\end{tabular}

Table III presents the maximum voltage dip at the PCC as a percentage of steady-state voltage. Similar to scenario 1, due to the reactive power support with the increasing penetration of $\mathrm{SG}$, voltage dip reduces.

\section{Microgrid BeHAVIOUR DuRING FAUlts}

\section{A. During grid connected and islanded mode}

A three-phase short-circuit fault was applied to bus 634 at $t=120 \mathrm{~s}$ and cleared after $150 \mathrm{~ms}$ during both grid connected and islanded modes. Total active power was supplied by SG and DFIG each having a 2.5 MVA capacity.

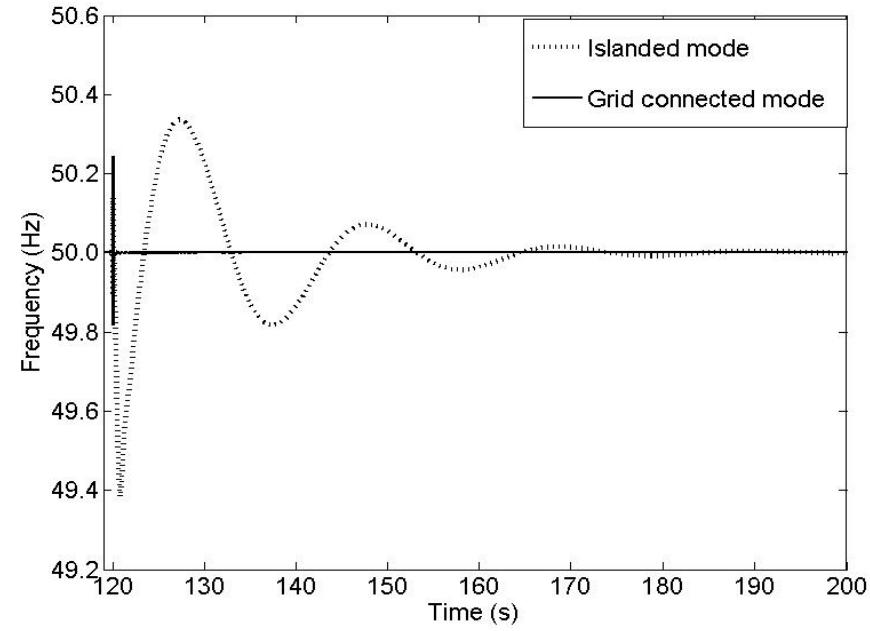

Fig. 6. Microgrid frequency variations due to a three-phase short-circuit fault.

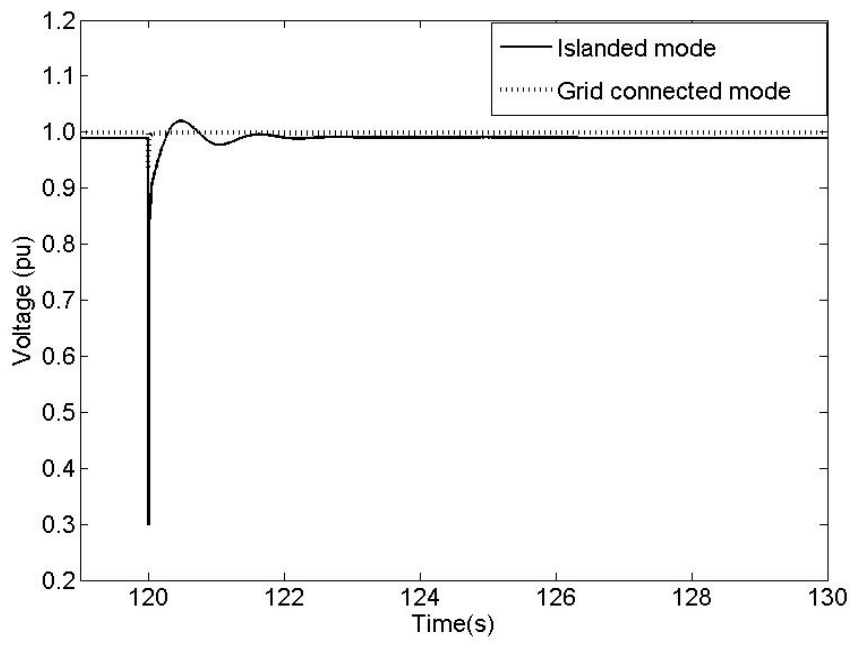

Fig. 7. Voltage variations at bus $632 \_1$ due to a three-phase short-circuit fault.
Post fault frequency and voltage of the grid connected microgrid recovers quickly after clearing the fault due to the active and reactive power support provided by the grid (refer to Fig. 6 and Fig. 7). However, during islanded mode frequency and voltage recovery times are significantly higher, since during islanded mode voltage and frequency support is provided by the SG. Moreover, both magnitude and the damping time of power frequency oscillations are exacerbated in islanded mode due to the less damping power in the microgrid (refer to Fig. 6). The voltage at the PCC has reduced significantly during islanding mode $(0.3 \mathrm{pu})$ due to lack of dynamic reactive power support in the microgrid (refer to Fig. 7).

\section{B. Effects of external grid short-circuit capacity}

The impact of external grid short-circuit capacity (SCC) on microgrid dynamic characteristics during faults are analysed by applying a three-phase short-circuit fault at bus 634 at $t=1 \mathrm{~s}$ for $150 \mathrm{~ms}$. Active power demand of the microgrid was supplied by SG and DFIG/PV each having a $2.5 \mathrm{MVA}$ capacity. The SCC of the external grid was varied in order to study the external grid impact on dynamic behaviour of the microgrid.

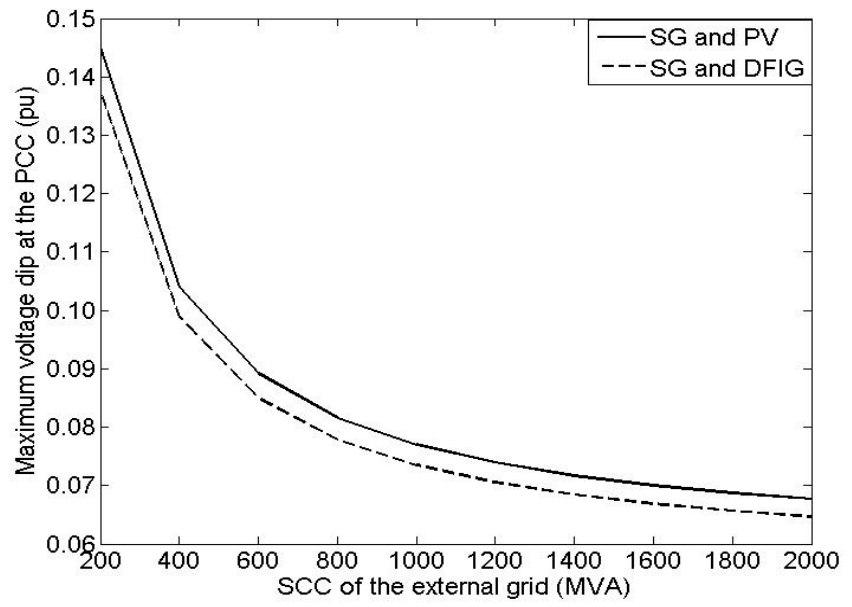

Fig. 8. Variations of maximum voltage dip at PCC with external grid SCC.

According to Fig. 8, the microgrid with DFIG and SG demonstrate large voltage drop in comparison to PV and SG. This can be explained as follows; during the fault, voltage drop in the DFIG stator windings produces sudden changes in stator flux resulting rapid increase in stator current. Due to the magnetic coupling between the stator and the rotor, high current will flow in the rotor and converter. In order to protect from high currents, crowbar resistors are used to bypass the converters. Activation of these crowbar resistors converts the DFIG into a squirrel cage induction generator which consumes more reactive power during voltage dips [20]. Consequently, high reactive power absorption result in larger voltage drop within the microgrid. However, PV systems do not have such reactive power requirement; hence provide better performance during voltage dips.

\section{Effect of external grid inertia}

Similar to the previous scenario, the same fault was applied in the microgrid and maximum ROCOF was observed for different external grid inertia. Fig. 9 illustrates the 
frequency behaviour of the microgrid due to a three-phase short-circuit fault for particular external grid inertia. Due to fast electronic controls in both DFIG and PV, inertial response is provided only by the SG which has a dominant effect on damping of frequency oscillations.

By analysing the results in Table IV, it is evident that external grid inertia does not have a significant impact on maximum ROCOF for a particular combination of REGs. However, the microgrid with DFIG and SG has indicated higher ROCOF values compared to microgrids with PV and SG.

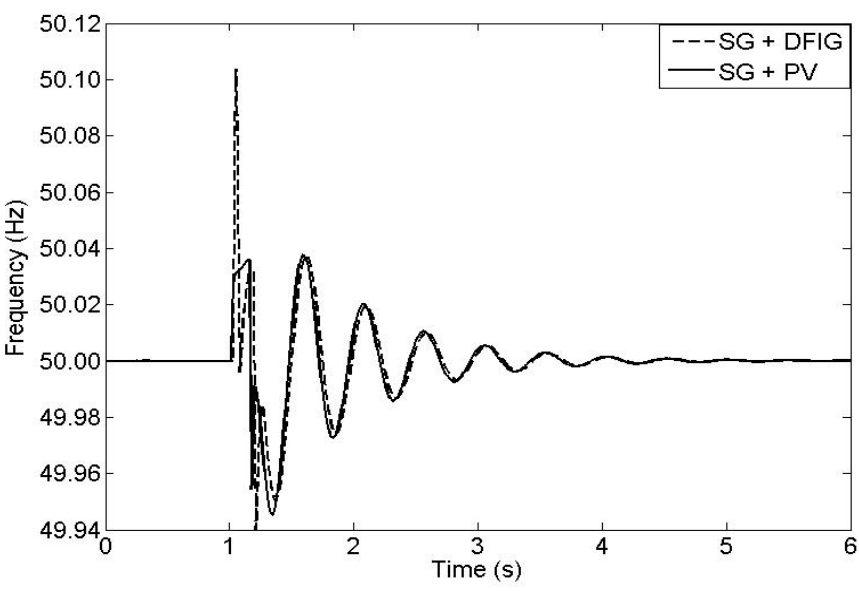

Fig. 9. Microgrid frequency variations during a three phase short circuit fault at $t=1 s$. (External grid inertia $=14 \mathrm{~s})$

TABLE IV

Maximum ROCOF with SG, DFIG and PV

\begin{tabular}{|c|c|c|}
\hline \multirow{2}{*}{$\begin{array}{l}\text { External grid inertia } \\
\text { constant (s) }\end{array}$} & \multicolumn{2}{|c|}{ Maximum ROCOF (Hz/s) } \\
\hline & With SG and DFIG & With SG and PV \\
\hline 2 & 0.2233 & 0.0685 \\
\hline 6 & 0.2252 & 0.0684 \\
\hline 10 & 0.2258 & 0.0681 \\
\hline 14 & 0.2261 & 0.0679 \\
\hline 18 & 0.2263 & 0.0678 \\
\hline
\end{tabular}

\section{CONCLUSIONS}

This paper presents a comparative dynamic analysis between different renewable energy generators connected to a microgrid. The study has shown that the dynamic characteristics of the microgrid are significantly influenced by the individual characteristics of renewable energy generators. Penetration of non-inverter based REGs has a significant effect on improving the oscillatory behaviour of the microgrid due to the emulated damping provided by the fast current controller. Further, studies have shown that different power dispatch levels, generator MVA capacity, and external grid characteristics also influence the dynamic behaviour of the microgrid, thus these factors should be considered when planning microgrids, and in particular designing protection systems for the microgrid. The importance of having dynamic reactive power support in a microgrid for voltage stability improvement was also highlighted in this study.

Future research activities will be carried out with experimental data in order to investigate the dynamic behaviour of a microgrid with various control capabilities for inverter interfaced renewable energy generators.

\begin{tabular}{|c|c|}
\hline \multicolumn{2}{|c|}{$\begin{array}{c}\text { VII. APPENDIX } \\
\text { TABLE V } \\
\text { Microgrid parameters }\end{array}$} \\
\hline $\mathrm{O} / \mathrm{H}$ Line impedance & $(0.3+\mathrm{j} 0.3) \Omega / \mathrm{km}$ \\
\hline Transformer-XFM1 & 1 MVA,4.16/0.48 kV,50 Hz \\
\hline 2 Winding $t / f$ & $10 \mathrm{MVA}, 115 / 4.16 \mathrm{kV}, 50 \mathrm{~Hz}$ \\
\hline Capacitor bank C 611 & 0.9MVAr \\
\hline Capacitor bank C 675 & $0.6 \mathrm{MVAr}$ \\
\hline Ext. grid short circuit power & 2500 MVA \\
\hline
\end{tabular}

\section{REFERENCES}

[1] J. A Pecas Lopes, N. Hatziargyriou, J. Mutale, P. Djapic and N. Jenkins, "Integrating distributed generation into electric power systems; A review of drivers, challenges and opportunities," Electric Power Systems Research, vol. 77, no. 9, pp. 1189-1203, Jul. 2007.

[2] G. Venkataramanan and C. Marnay, "A larger role for microgrids," IEEE Power \& Energy Mag., vol. 6, no. 3, pp. 78-82, May/ Jun. 2008.

[3] N. W. A. Lidula and A. D. Rajapakse, "Microgrids research: a review of experimental microgrids and test systems," Renewable and Sustainable Energy Reviews, vol. 15, no. 1, pp. 186-202, Jan. 2011.

[4] J. Driesenc and F. Karrie, "Design for distributed energy resources," IEEE Power \& Energy Mag., vol. 6, no. 3, pp. 30 - 40, May/ Jun. 2008.

[5] F. Katiraei, R. Irvani, N. Hatziargyriou and A. Dimeas, "Microgrid management," IEEE Power \& Energy Mag., vol. 6, no. 3, pp. 54-65, May/ Jun. 2008.

[6] N. Hatziargyriou, H. Asano, R. Iravani and C. Marnay, "Microgrids," IEEE Power \& Energy Mag., vol. 5, no. 4, pp. 78 - 94, Jul./ Aug. 2007.

[7] J. C. Vasquez, J. M. Guerrero, J. Miret, M. Castilla and L. G. de Vicuña, "Hierarchical control of Intelligent Microgrids," IEEE Industrial Electronics Mag., vol. 4, no. 4, pp. 23-29, Dec. 2010.

[8] F. Katiraei, M. R. Iravani and P. W. Lehn, "Micro-grid autonomous operation during and subsequent to islanding process," IEEE Trans. Power Delivery, vol. 20, no. 1, pp. 248- 257, Jan. 2005.

[9] F. Katiraei and M. R. Iravani, "Power Management Strategies for a Microgrid with Multiple Distributed Generation Units," IEEE Trans. Power Systems, vol. 21, no. 4, pp.1821-1831, Nov. 2006.

[10] D. Lee and L. Wang, "Small-Signal Stability Analysis of an Autonomous Hybrid Renewable Energy Power Generation/Energy Storage System Part I: Time-Domain Simulations," IEEE Trans. Energy Conversions, vol. 23, no. 1, pp. 311-320, Mar. 2008.

[11] N. Pogaku, M. Prodanovic and T. C. Green, "Modeling, Analysis and Testing of Autonomous Operation of an Inverter-Based Microgrid," IEEE Trans. Power Electronics, vol. 22, no. 2, pp. 613-625, Mar. 2007.

[12] M. Dewadasa, A. Ghosh, and G. Ledwich, "Dynamic response of distributed generators in a hybrid microgrid," in Proc. IEEE Power \& Energy Society General Meeting, pp. 1-9, Jul. 2011.

[13] M. Shahabi, M. R. Haghifam, M. Mohamadian and S. A. Nabavi-Niaki, "Microgrid Dynamic Performance Improvement Using a Doubly Fed Induction Wind Generator," IEEE Trans. Energy Conversions, vol. 24, no. 1, pp. 137-145, Mar. 2009.

[14] Z. Miao, A. Domijan and Lingling Fan, "Investigation of Microgrids with Both Inverter Interfaced and Direct AC-Connected Distributed Energy Resources," IEEE Trans. Power Delivery, vol. 26, no. 3, pp. 1634-1642, Jul. 2011.

[15] IEEE PES Distribution system analysis subcommittee, IEEE 13 node Test Feeder, [Online]. Available: http://ewh.ieee.org/soc/pes/dsacom/testfeed ers/index.html

[16] P. Kundur, Power System Stability and Control, McGraw-Hill, 1994.

[17] I.C. Report, "Excitation system models for power system stability studies," IEEE Trans. Power Apparatus and Systems, vol. PAS-100, no. 2, pp. 494-509, Feb. 1981.

[18] A.D. Hansen, C. Jauch, P. Sorensen, F. Iov, and F. Blaabjerg, "Dynamic wind turbine models in power system simulation tool DIgSILENT," Risø report Risø-R-1400(EN), Denmark, 2004.

[19] Information Technology Industry Council, "ITI (CBEMA) Curve Application Note," Washington DC, USA, [Online]. Available: http://www.itic.org.

[20] L. Meegahapola, T. Littler, D. Flynn, "Decoupled-DFIG fault ridethrough strategy for enhanced stability performance during grid faults," IEEE Trans. Sustainable Energy, vol. 1, no. 3, pp. 152-162, Oct. 2010. 